\title{
Effect of Some Host and Microclimate Factors on Infection of Tomato Stems by Botrytis cinerea
}

\author{
T. M. O'Neill, D. Shtienberg, and Y. Elad, Department of Plant Pathology, Agricultural Research Organization, \\ The Volcani Center, P.O. Box 6, Bet Dagan 50250, Israel
}

\begin{abstract}
O'Neill, T. M., Shtienberg, D., and Elad, Y. 1997. Effect of some host and microclimate factors on infection of tomato stems by Botrytis cinerea. Plant Dis. 81:36-40.

The susceptibility of tomato stems to infection by Botrytis cinerea and the influence of temperature and humidity on disease development were investigated with stem pieces and whole plants. Stem rotting resulted after inoculation of wounded stems with a conidial suspension in water or with dry conidia; no symptoms developed following inoculation of unwounded stems. The proportion of inoculated stems developing Botrytis rot increased as the inoculum concentration was increased from 10 to 10,000 conidia per stem. Stem susceptibility to infection declined from 60 to $8 \%$ as wound age increased from 0 to $24 \mathrm{~h}$ before inoculation. Wounded stem pieces maintained in a low vapor pressure deficit (VPD) environment $(<0.2 \mathrm{kPa})$ remained susceptible for a longer period than those maintained at a high VPD. Infection and stem rotting occurred at temperatures of 5 to $26^{\circ} \mathrm{C}$, with disease development most rapid at $15^{\circ} \mathrm{C}$. Sporulation was optimal at $15^{\circ} \mathrm{C}$ and did not occur within 20 days of incubation at 5 or $26^{\circ} \mathrm{C}$. Incubation at high humidity following inoculation of fresh wounds (VPD $<0.2 \mathrm{kPa}$ ) did not increase infection incidence or tissue rotting, compared with incubation at a VPD $>1.3 \mathrm{kPa}$; however, incubation at the lower VPD did increase the intensity of sporulation.
\end{abstract}

Additional keywords: gray mold, Lycopersicon esculentum, wound infection

Botrytis cinerea Pers.:Fr. is a ubiquitous pathogen that causes severe losses in many fruit, vegetable, and ornamental crops (21) and is particularly important in greenhouse production of vegetables $(14,19)$. The pathogen infects leaves, stems, flowers, and fruits. Stems of plants can be infected either by invasion by the fungus through the petiole (Y. Elad and D. Shtienberg, unpublished) or by direct infection of wounds after pruning and harvesting (23). Stem infection by $B$. cinerea may ultimately girdle the stem, kill the entire plant, and cause substantial yield losses $(15,28)$. Stem infections may be quiescent for up to 12 weeks $(15,19,24)$ before becoming aggressive.

Corresponding author: Y. Elad; Tel 9723 9683580; Fax 9723 9683543; E-mail: VPELADY@VOLCANI.AGRI.GOV.IL

Permanent address of first author: ADAS Horticulture, Brooklands Avenue, Cambridge CB2 2BL, England

Contribution from the Agricultural Research Organization, The Volcani Center, Bet Dagan, Israel No. 1708-E 1995 series.

The research is supported by a grants from The Dutch-Israeli Agricultural Research Program (DIARP) and the Chief Scientist at the Israeli Ministry of Agriculture.

Accepted for publication 24 September 1996.

Publication no. D-1996-1028-09R

(c) 1997 The American Phytopathological Society
High relative humidity (RH), free moisture on plant surfaces, and moderate temperatures are considered the most important environmental factors that promote infection by $B$. cinerea $(1,18,25)$, but reports on precise moisture requirements for infection are contradictory (9). Optimum temperatures for infection are between 10 and $20^{\circ} \mathrm{C}$, but infection can occur even at $2^{\circ} \mathrm{C}$ and above $25^{\circ} \mathrm{C}(6,11,14,17,20)$. Information on conditions influencing infection of tomato stems is scarce (8). Conidia of $B$. cinerea require nutrients for germination and for subsequent germ tube growth on the host surface, and restricted availability of nutrients results in a reduced infection rate $(2,3,27)$.

Stem rotting caused by $B$. cinerea has become an increasing problem in longseason (up to 11 months) crops of greenhouse-grown tomatoes in many countries in recent years $(7,9,28)$. It is a major problem where tomatoes are grown on highwire cropping systems and it is often a reason why a crop is finished earlier than planned. The disease also regularly causes losses in unheated and partially heated crops grown through the winter in Israel (10). A late epidemic in UK crops in 1994 resulted in an estimated loss of $£ 1.5$ million ( $\$ 2.3$ million) with individual greenhouses losing up to $40 \%$ of plants due to stem infection (T. M. O'Neill, unpublished). Information regarding host and microclimate conditions that affect tomato stem infection by $B$. cinerea is lacking. The objective of this work was to gain more precise information on the effects of host parameters (type of tissue and wounding), inoculum level, vapor pressure deficit (VPD), and temperature on infection of tomato stems by $B$. cinerea conidia.

\section{MATERIALS AND METHODS}

Plant material. Plug-raised tomato (Lycopersicon esculentum Mill., cv. 144) plants were grown in a peat/perlite/sand mixture $(1: 1: 1)$ in $17-\mathrm{cm}$ pots in a greenhouse maintained at 15 to $25^{\circ} \mathrm{C}$ during the day and night, and under commercial conditions in a peat/compost/tufa mixture placed in $1.2 \times 0.70 \times 0.25 \mathrm{~m}$ boxes placed in a polyethylene-covered greenhouse. Plants in pots were fertilized weekly with a fertilizer solution containing 5-3-8\% N-P$\mathrm{K}$ and plants in the commercial greenhouse were fertilized (5-3-8\% N-P-K) with every watering. No fungicides were applied to either crop. Side shoots, stems, and petioles were collected for inoculation experiments as required and were used immediately; side shoots were usually 40 to $50 \mathrm{~cm}$ in length and stems originated from plants of about $1.5 \mathrm{~m}$ height.

Botrytis cinerea. The isolate of the pathogen used was originally isolated from a naturally infected cucumber flower $(5,6)$ and maintained and grown on potato dextrose agar (PDA, Difco). This isolate sporulates abundantly in the dark and is capable of infecting various plant hosts, including tomato. Suspensions of conidia $\left(5 \times 10^{5}\right.$ per $\mathrm{ml}$, unless stated otherwise $)$ were prepared from 10- to 14-day-old cultures grown at $20^{\circ} \mathrm{C}$ in the dark by agitating a piece of sporulating culture in sterile, distilled water and filtering through folded muslin. Conidial concentration was determined with a hemacytometer and adjusted as necessary. In a preliminary experiment, the addition of glucose $(0.1 \mathrm{M})$ and potassium dihydrogen phosphate $(0.07 \mathrm{M})$ increased the proportion of stem pieces developing infection, and these nutrients were therefore added in most subsequent experiments.

Stem-piece experiments. The stempiece bioassay was a modified version of that used in earlier studies $(8,16)$. The top $10 \mathrm{~cm}$ of stems and side shoots was discarded and the remainder was cut with tomato snippers into 10 pieces, each $3 \mathrm{~cm}$ in length. Twenty pieces were inserted vertically into a $10-\mathrm{cm}$-diameter pot containing autoclaved perlite previously wet with distilled water to a known weight $(230 \mathrm{~g})$. 
The surface of the wound was inoculated. Each replicate pot contained equal numbers of pieces of tissue of different ages. There was one exception to this method of stem preparation: in experiments dealing with the susceptibility of unwounded tissue, stem pieces were inserted horizontally in pre-moistened floral foam and inoculation was done along the length of intact stem. Petiole pieces were prepared by removal of leaflets from fully expanded leaves on the main stem. Pots containing perlite or blocks of floral foam, each bearing stem pieces, were placed in plastic boxes $(380 \times 330 \times 160 \mathrm{~mm})$ and these were enclosed in a polyethylene bag and placed in an illuminated $\left(10 \mathrm{~J} \mathrm{~cm}^{-2} \mathrm{~h}^{-1}\right.$ at table level) walk-in growth room with fan ventilation, maintained at about $20 \pm$ $1.5^{\circ} \mathrm{C}$.

Inoculation of stem pieces and disease assessment. Stem pieces were individually inoculated with $20 \mu \mathrm{l}$ of conidial suspension by means of a micro-pipette; controls were inoculated with water or nutrient solution as appropriate. In a preliminary experiment, stem pieces were inoculated with dry conidia by touching each stem piece once with a tomato stem piece covered with sporulating $B$. cinerea. In experiments on wound age, pots with stem pieces were prepared at the requisite time periods before inoculation; boxes were then covered with a polyethylene bag or left uncovered, as required, and were placed in an illuminated growth room at $20^{\circ} \mathrm{C}$, or at the desired temperature.

Stem pieces were assessed 2, 4, 5, 6, 8, and 10 days after inoculation for incidence of infection, extent of tissue rotting, and degree of sporulation. The following scales were used. Stem infection: $0=$ stem end green; 1 = stem end brown or black; $2=$ up to $5 \mathrm{~mm}$ of stem length discolored; $3=6$ to $15 \mathrm{~mm}$ of stem length discolored; $4=>15$ $\mathrm{mm}$ of stem length discolored. Sporulation: $0=$ no sporulation; $1=$ sporulation on stem end only; 2 sporulation on up to $25 \%$ of stem length; $3=$ sporulation on 25 to $75 \%$ of stem length; $4=$ sporulation on $>75 \%$ of stem length. A mean infection index (0 to 4 ) and a mean sporulation index (0 to 4) were also calculated. A stem was considered infected if it had an infection index and/or a sporulation index $>1$. All stem pieces, including noninfected ones, were taken into account when calculating infection and sporulation indices.

The relationship of the scale used for assessing sporulation (index 0 to 4 ) to the quantity of conidia was investigated with sporulating stem pieces collected 10 days after inoculation at $20^{\circ} \mathrm{C}$ and low VPD $(<0.2 \mathrm{kPa})$. The quantity of conidia was determined by agitating 10 stem pieces of each grade in $50 \mathrm{ml}$ of sterile, distilled water and determining the resultant conidial concentration.

Whole-plant experiments. Whole-plant inoculation experiments were carried out in a greenhouse compartment maintained at $20 \pm 2^{\circ} \mathrm{C}$. Six-week-old plants were inoculated at wound sites created by cutting off leaf petioles adjacent to the stem, or by cutting off stem tops immediately above a leaf. There were five inoculation sites on each plant: one leaf removed from each canopy (lower, middle, and upper); the top of the main stem; and one side shoot. Wounds were inoculated with a 15- $\mu$ l droplet of conidial suspension in water and plants were then covered with a clear polyethylene bag for 5 days. Treatments consisted of inoculation of fresh wounds and of wounds created $1,3,6$, and 13 days previously.

Wounds on whole plants inoculated with $B$. cinerea were assessed 6 and 17 days after inoculation. Stems were regarded as infected when lesions greater than $5 \mathrm{~mm}$ in length were evident on cut stem ends or when stem discoloration and/or rotting extended more than $5 \mathrm{~mm}$ from the edge of a leaf scar. The lengths of lesions were measured.

Humidity regimes. Different RHs were produced by means of saturated salt solutions in distilled water as previously described (26). Pots of stem pieces were stood in glass petri dishes and the bases of incubation boxes were flooded to a depth of $5 \mathrm{~mm}$ with distilled water $(100 \% \mathrm{RH})$, $\mathrm{NaCl}(85 \% \mathrm{RH}), \mathrm{KCl}(75 \% \mathrm{RH})$, or glucose $(55 \% \mathrm{RH})$ and maintained at $20^{\circ} \mathrm{C}$. A very low RH $(<40 \%)$ was produced by placing uncovered boxes in a growth room with fan ventilation. The corresponding VPDs for these values of RH level were $<0.20,0.35,0.59,1.06$, and $>1.30 \mathrm{kPa}$. Two VPD levels were chosen for further study: stem pieces were incubated over distilled water in a closed polyethylene bag (VPD lower than $0.2 \mathrm{kPa}=$ high $\mathrm{RH}$ ), and in open boxes (VPD higher than $1.30 \mathrm{kPa}$ = low RH). Free moisture was maintained by spraying the stem pieces with water.

Experimental design and data analysis. Each of the experiments was repeated at least once. Since conclusions based on different trials of repeated experiments were similar, findings of one experiment are presented in the results. There were four to six replicates per treatment (pots with 20 stem pieces each) for the stem pieces experiments and eight replicates per treatment (plants) for the whole-plants experiments. Experiments were laid out in a completely randomized design. Data in percentages were arcsin transformed and treatments were compared statistically with Fisher's protected least significant difference test at $P \leq 0.05$.

\section{RESULTS}

Inoculation of wounds. Inoculation with a conidial suspension in water and with dry conidia each resulted in infection. Although symptom development was slightly more rapid following inoculation with a conidial suspension than with dry conidia, there was no difference in the final number of stems infected or the rate of tissue rotting. Dry inoculation was not quantitative and the suspension method was therefore preferred.

A high incidence of Botrytis rotting developed when freshly cut stem pieces or pieces of side shoots were inoculated with B. cinerea and incubated at $20^{\circ} \mathrm{C}$. No symptoms developed on intact (un-

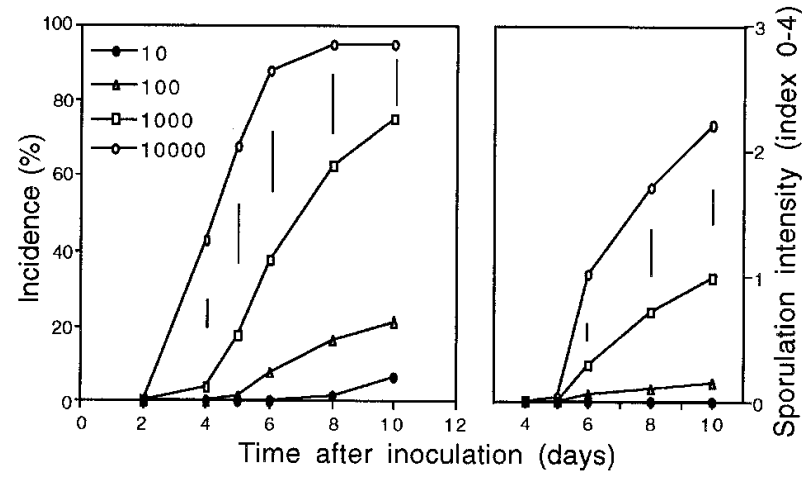

Fig. 1. Effect of concentration (number/wound) of Botrytis cinerea conidia on incidence of infection of tomato stem segments and on intensity of sporulation. Stem pieces were maintained at $20^{\circ} \mathrm{C}$ and vapor pressure deficit (VPD) $<0.2 \mathrm{kPa}$. Bars represent least significant difference for each sampling date.

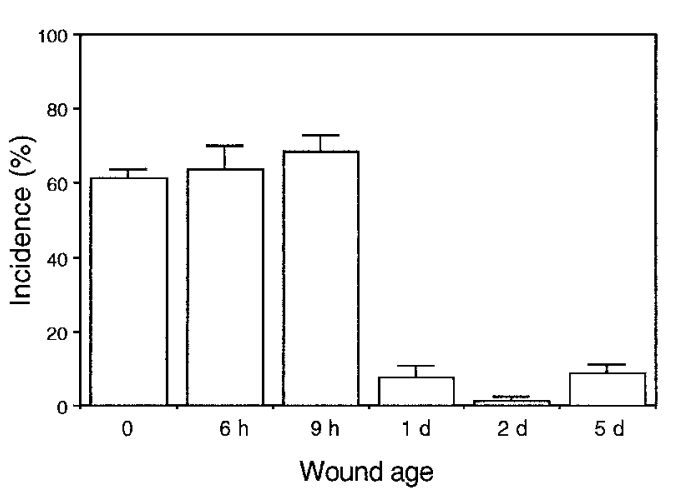

Fig. 2. Influence of wound age on incidence of infection of tomato stem pieces by Botrytis cinerea. Stem pieces were maintained at $20^{\circ} \mathrm{C}$ and vapor pressure deficit (VPD) $<0.2 \mathrm{kPa}$. Infections were recorded 10 days after each inoculation. Bars represent the SE. 
wounded) stem tissue 10 days after inoculation. Rot was usually first visible 2 to 3 days after inoculation and sporulation was visible after 4 to 5 days. When stem and side shoots from the same plant were inoculated, the numbers of pieces developing symptoms were similar but the rate of tissue rotting was greater in side shoots than in stems. Petioles were less susceptible than side shoots or main stems. The susceptibility of stem pieces inoculated at nodes and internodes did not differ significantly (results not shown). A significant ( $P$ $\left.\leq 0.01, R^{2}=0.998\right)$ nonlinear correlation $(Y$ $\left.=0.16-0.44 X+0.99 X^{2}\right)$ between the sporulation index $(X)$ and the number of conidia produced on tissue ( $Y$ in millions of conidia per stem) was obtained. Sporulation index was used in data analysis.

Infection of tomato stem pieces occurred when as few as $10 \mathrm{~B}$. cinerea conidia were applied to the surface of each stem wound (Fig. 1). Two higher inoculum levels $\left(10^{3}\right.$ and $10^{4}$ conidia per stem) resulted in very high incidences of stem infection (75 to 95\%) 10 days after inoculation whereas, at inoculum levels of 10 and $10^{2}$ conidia per stem, 7 and $20 \%$ of stems were infected, respectively, after this period. Inoculation with $10^{3}$ conidia per wound resulted in a sporulation index less than half of that observed after inoculation with $10^{4}$ conidia per wound. The two lower inoculum levels resulted in very poor sporulation on infected tissue (Fig. 1).

To determine the effect of wound age on susceptibility to infection, stem pieces were maintained for up to 5 days before inoculation with $B$. cinerea. Pieces maintained in a dry atmosphere for 1 day or more before inoculation were rarely susceptible to infection (incidence 2 to $8 \%$ ), whereas 60 to $70 \%$ of those inoculated 0 to $9 \mathrm{~h}$ after cutting became infected (Fig. 2).

The effects of wound age and inoculation position along the stem on the rate of disease development were evaluated by inoculating leaf scars at different canopy heights on 1-m-tall plants. The position of the leaf scar on the stem (lower, middle, and upper canopies) did not affect the incidence of infection, nor the length of the lesion. Therefore, results for different leaf scar positions were pooled. In general, lesion length decreased gradually with the aging of wounds at all infection sites (Fig. 3).

Effect of temperature and VPD on infection of stem pieces. Incubation tem- perature affected both the incidence of stem pieces developing infection and the intensity of sporulation (Fig. 4). Infection occurred at all the tested temperatures ( 5 to $26^{\circ} \mathrm{C}$ ) and was maximal at $15^{\circ} \mathrm{C}$. Sporulation was also maximal at $15^{\circ} \mathrm{C}$ but did not occur at 5 and $26^{\circ} \mathrm{C}$ by the end of the incubation period (Fig. 4).

Infection on stem pieces incubated at $20^{\circ} \mathrm{C}$ and VPDs of $<0.20,0.35,0.59$, and $1.06 \mathrm{kPa}$ developed similarly and reached 63 to $76 \%$ after 9 days of incubation. The development of infection was slightly slower under a VPD of $1.30 \mathrm{kPa}$ (only the two extreme VPD levels are presented in Figure 5). Under VPD regimes of $<0.20$ to $1.30 \mathrm{kPa}$, stem pieces developed Botrytis stem rot to a similar extent (severity indices 1.9 to 2.4). The intensity of sporulation differed between a VPD of 0 to $1.06 \mathrm{kPa}$ (represented by the low VPD conditions) and high VPDs (>1.30 $\mathrm{kPa})$ during 5 to 7 days after inoculation (Fig. 5). On stems maintained at a low VPD, sporulation developed first at the upper, cut end (at the point of inoculation) and gradually progressed down the stem pieces. Stems maintained in a dry environment developed sporulation later than stems in a humid en-

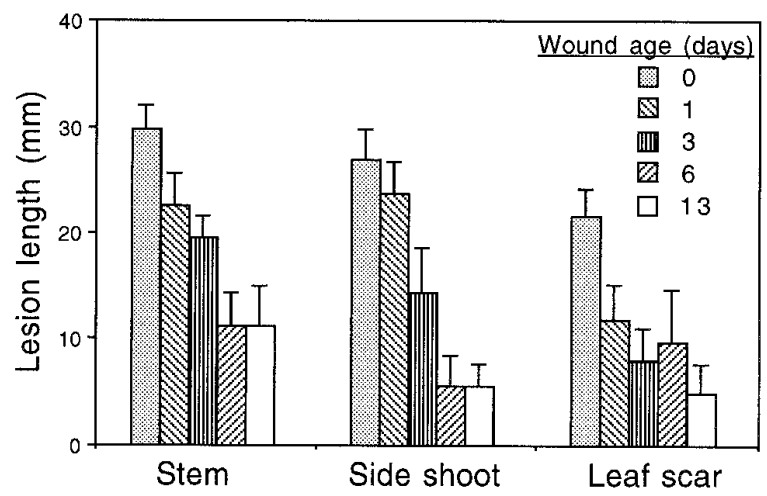

Fig. 3. Influence of wound age and plant organ on length of lesions incited by Botrytis cinerea on whole tomato plants. Plants were maintained at $20^{\circ} \mathrm{C}$ and vapor pressure deficit (VPD) $<0.2 \mathrm{kPa}$. Infections were recorded 17 days after each inoculation. Bars represent the SE.

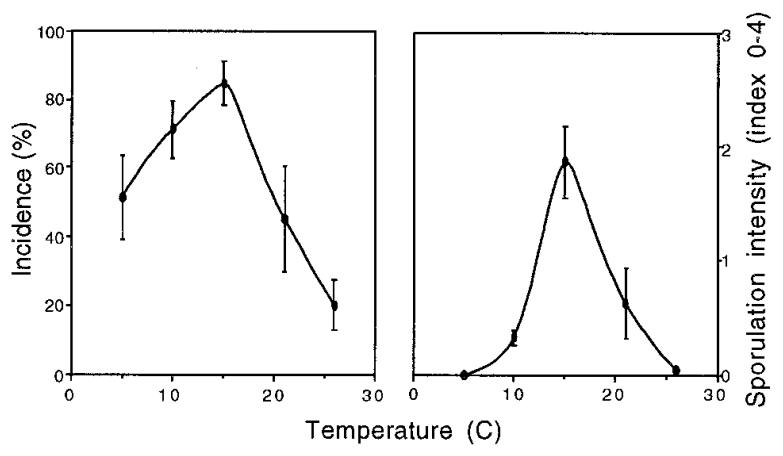

Fig. 4. Influence of temperature on incidence of infection of tomato stem pieces and on intensity of sporulation of Botrytis cinerea. Stem pieces were maintained at vapor pressure deficit (VPD) $<0.2 \mathrm{kPa}$. Bars represent the SE.

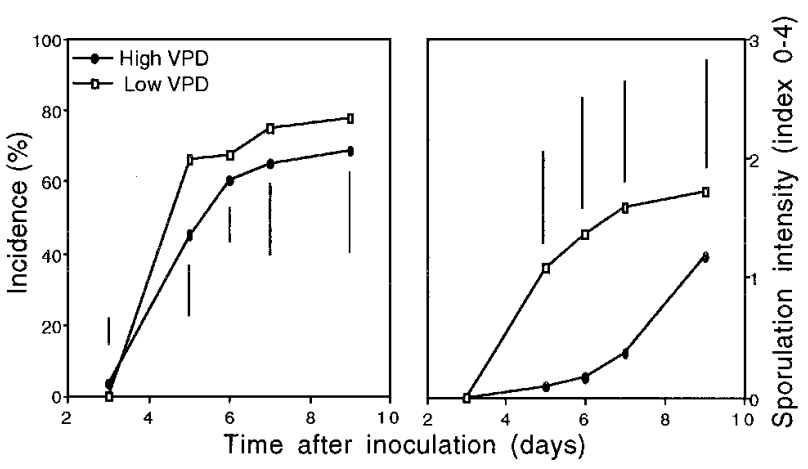

Fig. 5. Influence of vapor pressure deficit (VPD) on incidence of infection of tomato stem pieces and on intensity of sporulation of Botrytis cinerea. Low VPD $<0.2 \mathrm{kPa}$, High VPD > $1.3 \mathrm{kPa}$. Stem pieces were maintained at $20^{\circ} \mathrm{C}$. Bars represent least significant difference for each sampling date.

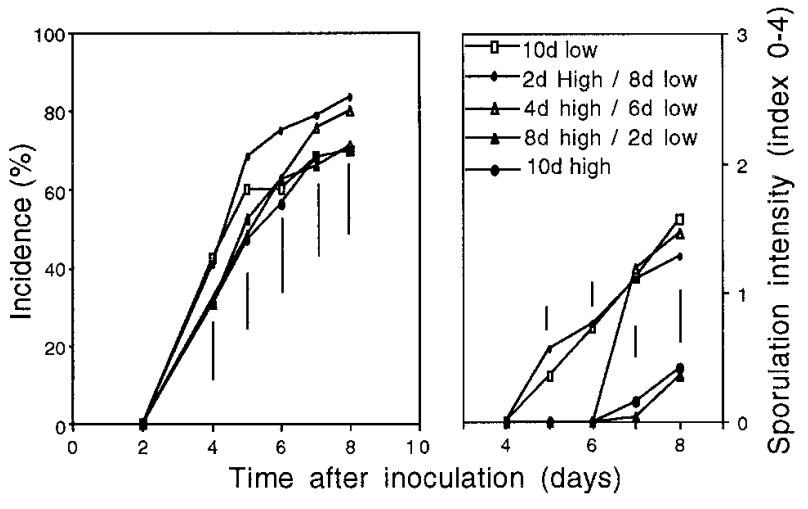

Fig. 6. Influence of switching between low and high vapor pressure deficit (VPD) periods on incidence of infection of tomato stem pieces and on intensity of sporulation of Botrytis cinerea. Low VPD $<0.2 \mathrm{kPa}$, High VPD $>1.3 \mathrm{kPa}$. Bars represent least significant difference for each sampling date. 
vironment and sporulation often occurred first on rotted stem tissue near the perlite surface, rather than at the inoculated end. Alternation between high and low VPD regimes during 10 days had no effect on the incidence of stem rot but did affect the extent of sporulation. Stems subjected to an initial high VPD period generally developed sporulation later than stems subjected to an initial low VPD (Fig. 6). When inoculated stem pieces were sprayed twice daily with water, the incidence of stem rot 9 days after inoculation was reduced to $12.5 \%$.

\section{DISCUSSION}

Stem lesions resulting from infection by $B$. cinerea are a distinct symptom of tomato gray mold, especially in long-season crops. They have become relatively important in recent years and a severe attack can result in a high incidence of plant death. In the course of the present research we studied the influence of two host parameters (the type of plant material and the age of wound at the time of inoculation), as well as temperature, VPD, and inoculum size, on infection of tomato stems by $B$. cinerea. Infection developed quickly on stem-piece wounds provided the pathogen inoculum was more than 1,000 conidia per wound (Fig. 1). However, even with as few as 10 conidia per wound, a small proportion of stems became infected. Dillon Weston and Taylor (4) reported that water droplets produced when water drips onto Botrytis-infected bean leaves contained up to 150 conidia per droplet. The number of conidia landing on stem wounds in commercial greenhouses from water splash and airborne inocula needs investigation.

In general, susceptibility to infection decreased with increasing wound age. The decline in susceptibility of stem pieces between 9 and $24 \mathrm{~h}$ was particularly marked and only 5 to $8 \%$ were infected when wounds 1 day old (or older) were inoculated (Fig. 2). Infection of leaf scars on growing plants led to a slower development of lesions than in stems or side shoots, but susceptibility persisted to some extent in all three tissues for at least 13 days (Fig. 3). Possibly the faster development on stems may be associated with an initial wound size greater than that of leaf scars. The fact that wounds on whole plants are susceptible a long time after wounding poses a challenge for control of Botrytis stem rot. The latent nature of tomato stem infections (24) further complicates management of the disease. Similar to the results presented here on tomato stem infection, Hausbeck and Pennypacker (13), working on stem blight of geranium, found that the longer the plants were maintained in an environment of high VPD before incubation in a dew chamber, the lower the stem blight incidence. However, unlike the geranium stem infection, which progressed mainly at low VPD, on tomato stems rotting also progressed at high VPD.

The effect of temperature on infection of tomato stem pieces by $B$. cinerea observed in this research (Fig. 4) was similar to the reported effect on infection of other plant organs and other hosts; i.e., the optimum temperatures for infection of flowers, fruits and leaves are between 10 and $20^{\circ} \mathrm{C}$, but infection could occur even at $2^{\circ} \mathrm{C}$ and above $25^{\circ} \mathrm{C}(6,11,14,15,17,20)$.

Low VPD, free moisture on plant surfaces, and cool weather are considered the most important environmental factors that promote infection by $B$. cinerea (1), but reports on precise moisture requirements for infection are contradictory (9). In the present study it was demonstrated that stem wounds could be infected even at a VPD as high as $1.30 \mathrm{kPa}$ and that infection developed at a similar rate under low and high VPD conditions (Fig. 5). Fluctuation between low and high VPD regimes had insignificant effects on disease development (Fig. 6). One of the alternative methods to control $B$. cinerea diseases currently practiced in greenhouses is prevention of canopy wetness by intensive heating and ventilating (18). This is in general effective against infection of leaves, flowers, and fruits, but not against stem infections. The reason for the failure to prevent stem wound infection by drying the ambient air probably lies in the fact that the moisture supplied by the wound itself may be sufficient to support the germination of $B$. cinerea conidia and the initial process of penetration. A similar phenomenon was observed with cucumber fruits that were infected at RHs as low as 70\% (VPD of 0.71 $\mathrm{kPa})$ (27). With cucumber fruits it was demonstrated that under dry conditions there was a constant supply of liquid that supported the germination of $B$. cinerea conidia. The cucumber fruits behaved similarly to tomato stem wounds in that an excess of moisture reduced the infection rate. This may result from the washing away of nutrients that may support the germination of pathogen conidia on the wound (27).

There is a lack of information regarding the effect of microclimate parameters on the production of conidia on plant tissues infected by $B$. cinerea $(9,12,14)$. It was studied recently by Sosa-Alvarez et al. (22) for strawberry leaf residues. They found that total hours of wetness and the duration of individual wet periods had the greatest effect on the amount of inoculum produced by $B$. cinerea at the optimal temperatures of 15 to $22^{\circ} \mathrm{C}$. In the present work, sporulation of $B$. cinerea on infected tomato stem wounds developed about 2 to 4 days after the appearance of rot symptoms (Fig. $1)$. The intensity of sporulation depended on the inoculum pressure (Fig. 1) and on the conditions under which the rotted stems were incubated (Figs. 4-6). The range of temperatures suitable for conidial production was narrower than the range promoting infection. Furthermore, although interruption of a low VPD $(<0.2$ $\mathrm{kPa}$ ) by up to 8 days of high VPD did not prevent infection, it significantly delayed the development of conidia on the rotted stem pieces (Fig. 6). It may be concluded that under dry conditions sporulation is suppressed although development of stem infection can occur. A reduction in sporulation may slow epidemic progress in a commercial greenhouse.

\section{ACKNOWLEDGMENTS}

Funding of T. M. O'Neill by the British Council and the sabbatical granted to him by ADAS are gratefully acknowledged. We appreciate the cooperation, fruitful discussions, and advice of A. J. Dik, J. Köhl, N. J. Fokkema, and A. Niv. The technical assistance of B. Kirshner and N. Gagulashvily is acknowledged.

\section{LITERATURE CITED}

1. Blakeman, J. P. 1980. Behavior of conidia on aerial plant surfaces. Pages $115-151$ in: The Biology of Botrytis. J. R. Coley-Smith, K. Verhoeff, and W. R. Jarvis, eds. Academic Press, London.

2. Blakeman, J. P. 1993. Pathogens in the foliar environment. Plant Pathol. 42:479-493.

3. Blakeman, J. P., and Brodie, I. D. S. 1976. Inhibition of pathogens by epiphytic bacteria on aerial plant surfaces. Pages 529-557 in: Microbiology of Aerial Plant Surfaces. C. H. Dickinson and T. F. Preece, eds. Academic Press, London.

4. Dillon Weston, W. A. R., and Taylor, R. E. 1948. Page 36 in: The Plant in Health and Disease. Crosby, Lockwood, London.

5. Elad, Y. 1988. Ultrastructural scanning electron microscopy study of parasitism of $\mathrm{Bo}$ trytis cinerea on flowers and fruit of cucumber. Trans. Br. Mycol. Soc. 97:185-190.

6. Elad, Y. 1989. Effect of abiotic conditions on development of grey mould of rose and scanning electron microscopy. Phytopathol. Mediterr. 28:122-130.

7. Elad, Y., Gullino, M. L., Shtienberg, D., and Aloi, C. 1995. Managing Botrytis cinerea on tomatoes in greenhouses in the Mediterranean. Crop Prot. 14:105-109.

8. Elad, Y., Köhl, J., and Fokkema, N. J. 1994 Control of infection and sporulation of $\mathrm{Bo}$ trytis cinerea on bean and tomato by saprophytic yeasts. Phytopathology 84:1193-1200.

9. Elad, Y., and Shtienberg, D. 1995. Botrytis cinerea in greenhouse vegetables; chemical, cultural, physiological and biological controls and their integration. Integr. Pest Manage. Rev. 1:15-29.

10. Elad, Y., Shtienberg, D., Yunis, H., Mahrer, Y. 1992. Epidemiology of grey mould in vegetable greenhouses. Pages 147-158 in: Recent Advances in Botrytis Research, K. Verhoeff, N. E. Malathrakis, and B. Williamson, eds., Pudoc Scientific Publishing, Wageningen, The Netherlands.

11. Elad, Y., Yunis, H., and Mahrer, Y. 1989. Effect of climatic conditions in polyethylenecovered structures on grey mould disease of winter cucumber. Appl. Agric. Res. 3:243247.

12. Epton, H. A. S., and Richmond, D. V. 1980. Formation, structure and germination of conidia. Pages 41-83 in: The Biology of Botrytis. J. R. Coley-Smith, K. Verhoeff, and W. R. Jarvis, eds. Academic Press, London.

13. Hausbeck, M. K., and Pennypacker, S. P. 1991. Influence of time intervals among wounding, inoculation, and incubation on stem blight of geranium caused by Botrytis cinerea. Plant Dis. 75:1168-1172. 
14. Jarvis, W. R. 1980. Epidemiology. Pages 219250 in: The Biology of Botrytis. J. R. ColeySmith, K. Verhoeff, and W. R. Jarvis, eds. Academic Press, London.

15. Jarvis, W. R. 1989. Managing diseases in greenhouse crops. Plant Dis. 73:190-194.

16. Koning, G. P., and Köhl, J. 1995. Wound protection by antagonists against Botrytis stem rot in cucumber and tomato. Pages 313-316 in: Environmental Biotic Factors in Integrated Plant Disease Control. M. Manka, ed. The Polish Phytopathological Society, Poznan.

17. Marois, J. J., Redmond, J. C., and MacDonald, J. D. 1988. Quantification of the impact of environment on the susceptibility of Rosa hybrida flowers to Botrytis cinerea. J. Am. Soc. Hortic. Sci. 113:842-845.

18. Morgan, W. M. 1984. The effect of night temperature and glasshouse ventilation on the incidence of Botrytis cinerea in a late planted tomato crop. Crop Prot. 3:243-251.

19. O’Neill, T. M. 1994. Resurgence of tomato stem botrytis. Grower 122:54-55

20. Salinas, J., Glandorf, D. C. M., Picavet, E. D., and Verhoeff, K. 1989. Effect of temperature, relative humidity and age of conidia on the incidence of spotting on gerbera flowers caused by Botrytis cinerea. Neth. J. Plant Pathol. 95:51-64.

21. Schwinn, F. J. 1992. Significance of fungal pathogens in crop production. Pestic. Outlook 3:18-28.

22. Sosa-Alvarez, M., Madden, L.V., and Ellis, M. A. 1995. Effects of temperature and wetness duration on sporulation of Botrytis cinerea on strawberry leaf residues. Plant Dis. 79: 609-615.

23. Verhoeff, K. 1968. Effect of soil nitrogen level and methods of deleafing upon the occurrence of Botrytis cinerea under commercial conditions. Neth. J. Plant Pathol. 74:184-
194.

24. Wilson, A. R. 1963. Some observations on the infection of tomato stems by Botrytis cinerea Fr. Ann. Appl. Biol. 51:171.

25. Winspear, K. W., Postlethwaite, J. D., and Cotton, R F. 1970. The restriction of Cladosporium fulvum and Botrytis cinerea, attacking greenhouse tomatoes, by automatic humidity control. Ann. Appl. Biol. 65:75-83.

26. Winston, P. W., and Bates, D. H. 1960. Saturated solutions for the control of humidity in biological research. Ecology 41:232-237.

27. Yunis, H., and Elad, Y. 1993. Effect of microclimate and nutrients on development of cucumber gray mold (Botrytis cinerea). Phytoparasitica 21:257-268.

28. Yunis, H., Elad, Y., and Mahrer, Y. 1990. Influence of fungicide control of cucumber and tomato grey mould (Botrytis cinerea) on fruit yield. Pestic. Sci. 31:325-335. 